\title{
Larval Biometry of Simulium rubrithorax (Diptera: Simuliidae) and Size Comparison between Populations in the States of Minas Gerais and Roraima, Brazil
}

\author{
Miriam Adriana Alvan-Aguilar, Neusa Hamada ${ }^{+}$ \\ Coordenação de Pesquisas em Entomologia, Instituto Nacional de Pesquisas da Amazônia, Caixa Postal 478, \\ 69011-970 Manaus, AM, Brasil
}

\begin{abstract}
The number of larval instars of Simulium (Hemicnetha) rubrithorax Lutz (Diptera: Nematocera) was determined using the lateral length of the head capsule. In this study 1,035 larvae, of different sizes, were measured (639 from the state of Roraima and 396 from the state of Minas Gerais). A frequency distribution analysis was carried out on the measurements of the lateral length of the head capsule to determine the number of larval instars. The limits of each instar were defined by the lower frequency of the measurements falling in a range of values, by the presence of the "egg burster" that characterizes the first larval instar, and by the developmental stage of the gill histoblast. The determination of the instar number was tested using a Student's t-test $(p<0.05)$, the Dyar rule and the Crosby growth rule. The results indicate the existence of 7 larval instars for this species, although this result was not in accordance to the Crosby rule. Last-instar larvae from two widely separated geographical populations (Roraima and Minas Gerais), collected in habitats with different water temperature were compared and no differences ( $p>$ 0.05) were observed between them.
\end{abstract}

Key words: aquatic insects - biometry - black fly - larval instars - Simuliidae - Minas Gerais - Roraima - Brazil

Black flies (Diptera: Simuliidae) are holometabolous insects that undergo several ecdyses during their development (Crosskey 1990). Larvae of these insects are an important component in the bioenergetic cycle in lotic systems. In the adult stage, the females are potential vectors of etiological agents that can cause diseases in humans or bite in such large numbers and thereby causing economic damage to agriculture and tourism (Coscarón-Arias \& Bramardi 1996).

Knowledge of the number of larval instars and the biological cycle is necessary to understand the population dynamics of these species and to determine their community structure (Alencar et al. 2001a). Information on this subject is important in control programs of pest species, especially in black flies where population management targets the larval stage (Gray et al. 1996).

According to Crosskey (1990), the larval development of black flies is related to environmental conditions. Physical characteristics of the streams, such as temperature and food availability, are some of the factors that can affect black fly populations by reducing the period of development, the number of larval instars and the size of the larva at maturity (Ross \& Merritt 1978, Colbo \& Porter 1979, 1981, De Moor 1982). The number of larval instars in black flies is variable, ranging from 4 to 9 instars, the

This study received partial financial support from the PPI 13070 (MCT/INPA) and CNPq (grant 468942/00-9).

${ }^{+}$Corresponding author. Fax: + 55-92-642.8909. E-mail: nhamada@inpa.gov.br.

Received 5 November 2002

Accepted 26 March 2003 most common being 6 and 7 (Ross \& Merritt 1978, Ross \& Craig 1979, De Moor 1982, Hamada 1989, Coscarón-Arias \& Bramardi 1998, Cunha et al. 1998, Alencar 2001a, Santos 2001, Melo 2002). Also, the number of instars can vary in different populations of a species (Craig 1975, Ross \& Merritt 1978, Post 1983) and between female and male larvae (Craig 1975, Elouard 1978).

In insects, the number of larval instars is usually determined using sclerotized structures, which show minimal variation (Dyar 1890). In black flies, the structure used most frequently is the head capsule. The width and the lateral length of the head capsule are the most commonly used characteristics; both measurements are highly correlated (Alencar et al. 2001a). In Brazil few studies on larval instars of black fly species have been done (Hamada 1989, Cunha et al. 1998, Melo 2002) and only Gorayeb (1981) and Alencar et al. (2001a) included first-instar larvae in their analysis.

Simulium (Hemicnetha) rubrithorax Lutz, which is the subject of this study, is a large black fly species. Its last-instar larvae measure around $1.3 \mathrm{~cm}$ and it has zoophilic habits (Maia-Herzog et al. 1984, Shelley et al. 1997). Very little other information on its biology has been published. The objectives of this study are to determine the number of larval instars in S. rubrithorax and to verify if there are differences in the size of last-instar larvae of this species from two different populations, one from the Northern region of the country and the other from the Central region.

\section{MATERIALS AND METHODS}

The study areas included rapids and waterfalls in two streams with bedrock. The first is situated in the state of Roraima, Igarapé do Bananal $\left(04^{\circ} 25^{\prime} \mathrm{N}, 61^{\circ} 12^{\prime} \mathrm{W}\right)$, Pacaraima county and the other in the state of Minas 
Gerais, Cachoeira do Boné, Serra do Brigadeiro $\left(20^{\circ} 20^{\prime} \mathrm{S}\right.$, $42^{\circ} 20^{\prime} \mathrm{W}$ ), Araponga county. Sampling in Roraima was carried out in December 2000 (dry season), when the water temperature in the stream was $24^{\circ} \mathrm{C}$. In Minas Gerais, sampling was done in July 1997 (winter season); water temperature was not measured at the collection time, but water temperature in streams in this region in July can reach $14^{\circ} \mathrm{C}$ (PS Santos, person. commun.).

Larvae and eggs batches were collected directly from the rock substrate and preserved in $80 \%$ ethanol. $S$. rubrithorax was the only species collected in the studies sites, in this way we assume that all the eggs and larvae belonged to this species. Also, egg and larvae of all the instars had the dark colour characteristic of last-instar larvae of this species, not found in the other species collected in other streams in the study area.

The biometry was based on measurements of the lateral length of the head capsule of larvae of different sizes, from samples collected on the same day at each study site. These measurements were placed in a frequency distribution to visualize the number of larval instars. The limits of each instar were defined by means of the lower frequencies, the first instar being characterized by the presence of the "egg burster" on the head capsule of the larva (Fig. 1). The last-instar was characterized by the presence of a fully formed, dark gill histoblast (Fig. 2) (Elouard 1978, Ross \& Merritt 1978, De Moor 1982).

To verify the accuracy in the grouping process of the larval instars we used the Crosby growth rule (Craig 1975). This rule states that there is a possibility of an instar being lost when the difference between two consecutive Brook's ratio is larger than $10 \%$.

The Student's t-test $(\alpha=0.05)$ was used to compare the means between each larval instar and to make the size comparison between last-instar larvae of the populations from Roraima and Minas Gerais. To verify the rate and the pattern of growth during the larval stage, the mean of each instar defined was log transformed (base 10) and plotted against the number of the larval instar. Linear regression analysis was used to verify the geometric pattern of growth; according to Dyar's rule, any deviation from this line would indicate that some instar was absent (Ross \& Craig 1979, De Moor 1982, Hamada 1989, Cunha et al. 1998).

A

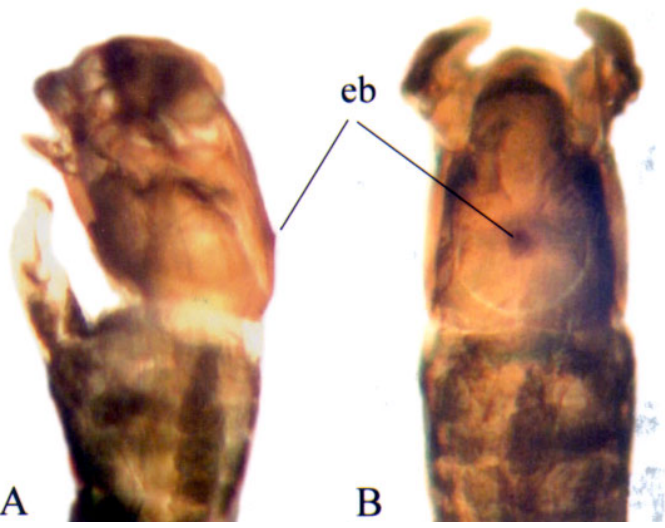

Fig. 1: first-instar larva of Simulium rubrithorax (Diptera: Simuliidae) with the egg burster (eb). A: lateral view; B: dorsal view
A

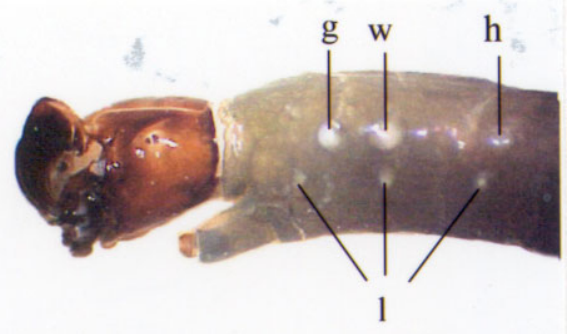

B

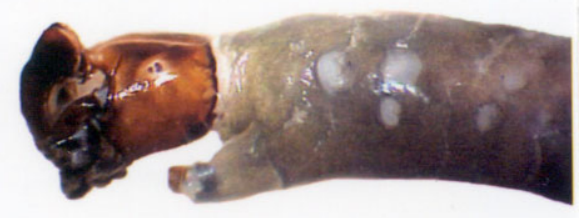

$\mathrm{C}$

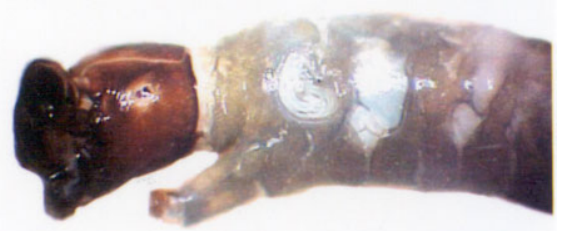

D

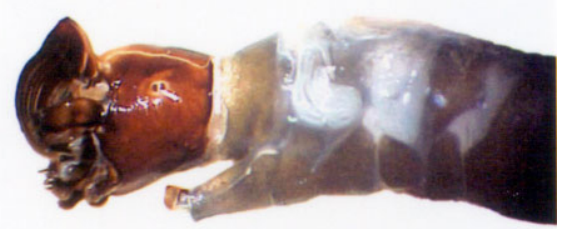

E

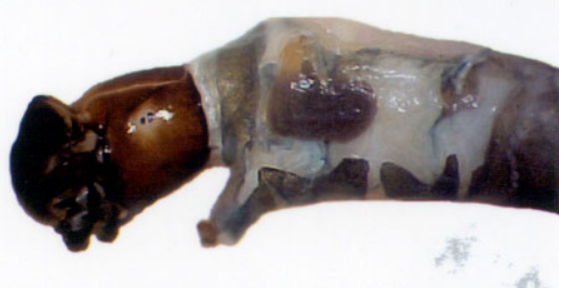

Fig. 2: last-instar larvae of Simulium rubrithorax (Diptera: Simuliidae) showing different developmental phases of the pupal gill (g), leg (l), wing (w) and halter (h) histoblasts. Development progresses from $\mathrm{A}$ to $\mathrm{E}$ and ends when the gill histoblast is completely formed and turns dark, at which point the larva is considered to be mature.

The growth rate between each instar was estimated using the formula $r=\operatorname{Ln}\left(\mathrm{N}_{\mathrm{t}} / \mathrm{N}_{\mathrm{o}}\right) / t$, where $\mathrm{r}=$ growth rate, $\ln =$ natural logarithm, $\mathrm{N}_{\mathrm{o}}=$ mean of the measurement of the structure in the preceding instar, $\mathrm{N}_{\mathrm{t}}=$ mean of the measurement of the structure in next instar and $t=$ the number of intervals between one instar and the other, which in this case was equal to one instar.

\section{RESULTS AND DISCUSSION}

In this study, 1,035 larvae of S. rubrithorax (639 from Roraima and 396 from Minas Gerais) were analyzed (Table I). The results indicate the existence of seven larval instars for this species. In the Minas Gerais population the first two instars were not collected during the sampling procedure, probably because the sampling technique did not allow the collection of the smaller size larvae. We recommend the use of a fine mesh net, to collect the speci- 


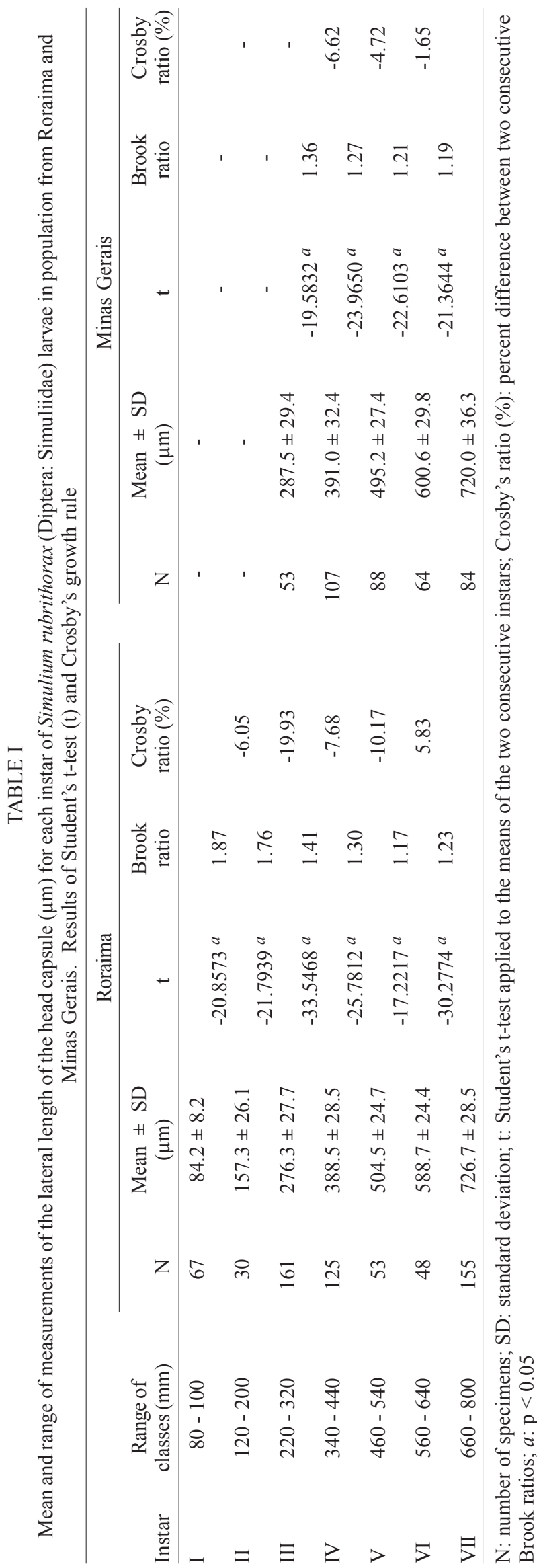

mens, especially where the population is smaller, increasing the probability of collecting all the instars.

First-instar larvae were obtained from the collected batches of eggs (Fig. 3) in Roraima. All of the larvae that had gill, leg, wing and halter histoblasts in different stages of development (Fig. 2) were considered last-instar larvae, since they have similar head capsule lateral length.

In Brazil, using this same structure, the existence of eight larval instars has been reported for Simulium rorotaense Floch \& Abonnenc (= Simulium fulvinotum Cerqueira \& Nunes de Mello) (Gorayeb 1981) and Simulium incrustatum Lutz (Cunha et al. 1998); seven for Simulium goeldii Cerqueira \& Nunes de Mello (Hamada 1989), Simulium acarayense Coscarón, Simulium orbitale Lutz, Simulium pertinax Kollar (Cunha et al. 1998), Simulium quadrifidum Lutz (Santos 2001) and Simulium perflavum Roubaud (Alencar et al. 2001a). For S. perflavum, Alencar et al. (2001a) also determined that there is no difference in the larval size between seasons and genders in Central Amazonia. Melo (2002) showed differences in two populations of Simulium oyapockense s.l. from the Amazon, where one had six and the other had seven larval instars.

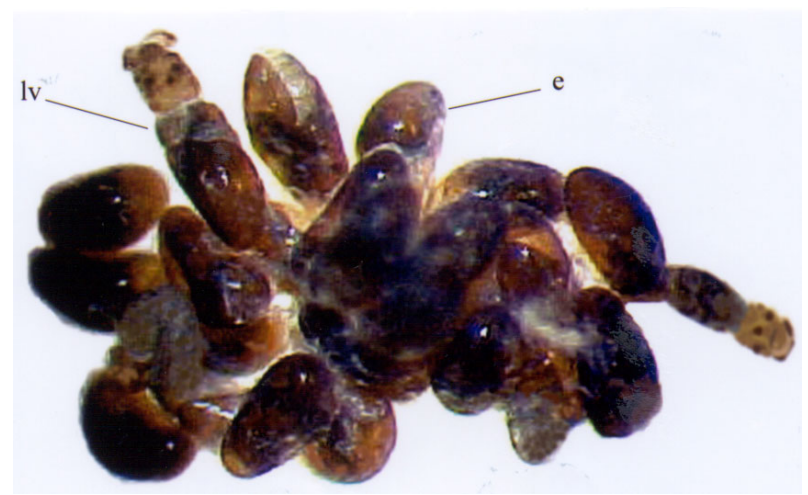

Fig. 3: batch of eggs of Simulium rubrithorax (Diptera: Simuliidae) with some first-instar larvae (lv) emerging from the eggs (e).

With the Student's t-test we verify that the means of the lateral length of the head capsule of each $S$. rubrithorax larval instar were significantly different $(\mathrm{p}<$ 0.05 ), indicating no overlap between the larval instars (Table I). Linear regression analysis provided the following equation for the Roraima population: $\log _{10} \mathrm{y}=1.8916$ $+0.1512 \mathrm{x}$, with $\mathrm{r}^{2}=0.924, \mathrm{n}=639$. This indicates a geometric growth for the seven larval instars determined, in accord with Dyar's rule.

Analyzing the population of Roraima we observed that the results were not in accordance with Crosby's rule since the Brook's ratio between the second and third larval instars was $19.9 \%$ (Table I), almost double the value indicated by Crosby's rule. In the population in Minas Gerais, the results were in accordance with Crosby's rule, however, first and second instars were missing in the analysis (Table I). Some of the other black fly biometric studies done in the Neotropical region also fail to show $100 \%$ agreement with Crosby's rule (Coscarón-Arias \& Bramardi 1998, Alencar et al. 2001a, Santos 2001, Melo 2002), al- 
though, the exceptions to the agreement with the Crosby's rule were not between the same instars in the species reported above, but rather occurred between the first and second, second and third, fourth and fifth instars.

The growth rate of the lateral length of the head capsule of S. rubrithorax larvae, in general, decreased when the instar number increased (Table III). In Brazil, other biometric studies have shown the same trend in $S$. rorotaense, S. goeldii, S. acarayense, $S$. incrustatum, $S$. orbitale, S. pertinax, S. perflavum, S. quadrifidum and $S$. oyapockense (Gorayeb 1981, Hamada 1989, Cunha et al. 1998, Alencar et al. 2001a, Santos 2001, Melo 2002) (Table III). The growth rate data of $S$. goeldii, $S$. quadrifidum and $S$. oyapockense were not included in the table because they have not yet been published.

Few biometric studies with black flies included firstinstar larvae. To get this instar it would be necessary to collect females with fertilized eggs and wait until larval eclosion. Other options would be to collect egg batches or larvae with "egg bursters" in the field, in habitats with only one species, because it is difficult to distinguish different species in the earliest instars, especially closely related species. Most workers considered that the smallest larvae collected, without egg bursters, were in the second instar (Hamada 1989, Cunha et al. 1998, Santos 2001, Melo 2002). However, comparing the available data (Table II) we may hypothesize that $S$. orbitale and $S$. acarayense may indeed have eight larval instars instead of seven. The second larval instars of these two species were quite large, compared with the second-instar larvae of S. perflavum and S. rubrithorax, the species with known first-instar larva.

In biometric studies in Brazil, only Gorayeb (1981) and
Alencar et al. (2001a) reported first-instar larvae, but the first author did not include the mean size of the larval instars. S. rubrithorax and S. perflavum have seven larval instars, in the first two instars, differences are almost nonexistent between the two species, but from the third to the seven instars the differences increase with each succeeding larval instar. The sizes of their head capsules at the last instar differ by a factor of 1.6 (Table II).

Many factors can affect the growth and development of insects, especially temperature, which can influence the development time, the number of larval instars and the larval size at maturity (Ross \& Merritt 1978). Colbo and Porter $(1979,1981)$ reported that, under laboratory conditions, the size of Simulium vittatum is affected by food availability and temperature. However, in the present study, last-instar larvae of $S$. rubrithorax collected in two streams, with water temperature differing by approximately $10^{\circ} \mathrm{C}$, did not show significant differences $(\mathrm{p}>0.05)$. Food availability for larval growth also must differ in these two habitats, since one is located in a forested area of the Amazon region in Northern Brazil and the other in a savanna area of Central Brazil. Alencar et al. (2001a), studying S. perflavum in the Amazon region, did not find differences in size and number of larval instars between populations collected in the rainy and dry seasons, although food type differed between habitat and season (Alencar et al. 2001b).

Although in temperate regions environmental factors such as water temperature and food seem to be correlated with the size of black fly larvae, our results suggest that environmental factors in the study area are either not related to size or that these environmental factors are not sufficiently different to affect the larval size.

TABLE II

Mean lateral length $(\mu \mathrm{m})$ of head capsule of Simulium spp. (Diptera: Simuliidae) larvae in Brazil

\begin{tabular}{lcccccc}
\hline Instars $^{\prime}$ & S. rubrithorax & S. acarayense $^{a}$ & ${\text { S. } \text { incrustatum }^{a}}^{a}$ & ${\text { S. } \text { orbitale }^{a}}$ & S. pertinax $^{a}$ & S. perflavum $^{b}$ \\
I & 84.2 & - & - & - & - & 104.2 \\
II & 157.3 & 204.1 & 130.4 & 256.5 & 184.6 & 159.2 \\
III & 276.3 & 246.8 & 188.3 & 333.6 & 221.6 & 217.6 \\
IV & 388.5 & 280.1 & 220.3 & 383.7 & 287.8 & 286.1 \\
V & 504.5 & 311.9 & 253.8 & 422.6 & 369.9 & 350.4 \\
VI & 588.7 & 352.1 & 290.1 & 474.2 & 437.9 & 408.9 \\
VII & 726.7 & 383.0 & 320.3 & 523.9 & 495.1 & 453.3 \\
VIII & & & 348.3 & & & \\
\hline
\end{tabular}

$a$ : Cunha et al. 1998; $b$ : Alencar et al. 2001a; -: data not reported

TABLE III

Growth ratio of the lateral length of head capsule of Simulium spp. (Diptera: Simuliidae) larvae in Brazil

\begin{tabular}{cccccccc}
\hline Instars & S. rubrithorax & S. rorotaense $^{a}$ & ${\text { S. } \text { acarayense }^{b}}^{\text {S. } \text {. }_{\text {incrustatum }}{ }^{b}}$ & ${\text { S. } \text { orbitale }^{b}}^{\text {S. pertinax }}{ }^{b}$ & S. perflavum $^{c}$ \\
\hline I - II & 0.63 & - & - & - & - & - & 0.42 \\
II - III & 0.56 & 1.25 & 0.19 & 0.36 & 0.26 & 0.18 & 0.31 \\
I II - IV & 0.34 & 1.24 & 0.12 & 0.15 & 0.14 & 0.26 & 0.27 \\
IV - V & 0.26 & 1.24 & 0.10 & 0.14 & 0.10 & 0.25 & 0.20 \\
V - VI & 0.15 & 1.23 & 0.12 & 0.13 & 0.11 & 0.16 & 0.15 \\
VI - VII & 0.21 & 1.16 & 0.08 & 0.10 & 0.09 & 0.12 & 0.10 \\
VII - VIII & & 1.11 & & 0.08 & & & \\
\hline
\end{tabular}

a: Gorayeb 1981; $b$ : Cunha et al. 1998; $c$ : Alencar et al. 2001a; -: data not reported 


\section{ACKNOWLEDGMENTS}

To Yamile Benaion Alencar for collecting the specimens in Minas Gerais and all the people who helped to collect specimens in Roraima, especially Jeferson Oliveira da Silva. Patrícia da Silva Santos provided water temperature information about streams in Serra do Brigadeiro (MG). Philip M Fearnside reviewed the manuscript.

\section{REFERENCES}

Alencar YB, Hamada N, Magni-Darwich S 2001a. Morphometric comparison of Simulium perflavum larvae (Diptera: Simuliidae) in relation to season and gender in Central Amazonia, Brazil. Mem Inst Oswaldo Cruz 96: 1-5.

Alencar YB, Ludwig TAV, Soares CC, Hamada N 2001b. Stomach content analyses of Simulium perflavum Roubaud 1906 (Diptera: Simuliidae) larvae from streams in Central Amazonia, Brazil. Mem Inst Oswaldo Cruz 96: 561-576.

Colbo MH, Porter GN 1979. Effects of food supply on the life history of Simuliidae (Diptera). Can J Zool 57: 301-306.

Colbo MH, Porter GN 1981. The interaction of rearing temperature and food supply on the life history of two species of Simuliidae (Diptera). Can J Zool 59: 158-163.

Coscaron-Arias CL, Bramardi SJ 1996. Determinación del número de estadios de tres espécies de Simuliidae (Diptera) del Parque Nacional Lanin (Neuquen, Argentina). Rev Soc Entomol Argent 55: 95-105.

Craig DA 1975. The larvae of Tahitian Simuliidae (Diptera: Nematocera). J Med Entomol 4: 463-476.

Crosskey RW 1990. Life in the water. In The Natural History of Blackflies, John Wiley \& Sons, The British Museum of Natural History, London, p. 89-245.

Cunha MCI, Coscarón S, Bassi RMA 1998. Determinación de los estadios larvales de Simulium (Diptera, Simuliidae) de Paraná, Brasil. Acta Biol Par 27: 57-66.

De Moor FC 1982. Determination of the number of instars and size variation in the larvae and pupae of Simulium chutteri Lewis 1965 (Diptera: Simuliidae) and some possible bionomical implications. Can J Zool 60: 1373-1382.

Dyar HG 1890. The number of molts lepidopterous larvae. Psyche 5: 420-422.

Elouard JM 1978. Identification biométrique des stades larvaires de $S$. damnosum et de $S$. ardesi (Diptera: Simuliidae).
Tropenmed Parasit 29: 183-187.

Gorayeb IS 1981. Comportamento de ovoposição e ciclo evolutivo de Simulium fulvinotum Cerq. \& Mello, 1968 (Diptera, Nematocera). Acta Amazonica 11: 595-604.

Gray EW, Adler PH, Noblet R. 1996. Economic impact of black flies (Diptera: Simuliidae) in South Carolina and development of a localized suppression program. J Am Mosq Control Assoc 12: 676-678.

Hamada N 1989. Aspectos Bioecológicos de Larvas de Simulium goeldii Cerqueira \& Nunes de Mello, 1967 com Referências a Larvas de Simulium rorotaense Floch \& Abonnenc, 1946 (Diptera: Simuliidae) na Reserva Florestal Ducke, Amazônia Central, MSc Thesis, INPA/FUA, Manaus, 106 pp.

Maia-Herzog M, Shelley AJ, Luna Dias APA, Malaguti R 1984. Comparação entre Simulium brachycladum e Simulium rubrithorax, suas posições no subgênero Hemicnetha e notas sobre uma espécie próxima, S. scutistriatum (Diptera: Simuliidae). Mem Inst Oswaldo Cruz 79: 341-356.

Melo GAP 2002. Biometria Larval de Duas Populações de Simulium oyapockense s. l. Diptera: Simuliidae) Provenientes de Paraíso (São Gabriel da Cachoeira, AM) e Cachoeira Bem-Querer (Caracarai, RR), MSc Thesis, INPA/FUA, Manaus, 69 pp.

Post R 1983. The annual cycle of Simulium erythrocephalum (Diptera: Simuliidae) at a site in Norfolk. Freshwater Biol 13: 379-388.

Ross DH, Craig DA 1979. The seven larval instars of Prosimulium mixtum Syme \& Davies and P. fuscum Syme \& Davies (Diptera: Simuliidae). Can J Zool 57: 290-300.

Ross DH, Merritt RW 1978. The larval instar and population dynamics of five species of black flies (Diptera: Simuliidae) and their responses to selected environmental factors. Can J Zool 56: 1633-1642.

Santos EM 2001. Estudo de Simuliidae (Diptera: Nematocera) e seus Criadouros em Igarapés do Município de Santo Antônio do Tauá, Estado do Pará, Brasil, MSc Thesis, UFPA, Belém, $110 \mathrm{pp}$.

Shelley AJ, Lowry CA, Maia-Herzog M, Luna-Dias APA, Moraes MAP. 1997. Biosystematic studies on the Simuliidae (Diptera) of the Amazonia onchocerciasis focus. Bull Nat Hist Mus 66: 1-124. 